Correspondence

Shinji Yamasaki

shinji@vet.osakafu-u.ac.jp

Received 20 September 2005 Accepted 3 January 2006

\section{Distribution and characterization of integrons in various serogroups of Vibrio cholerae strains isolated from diarrhoeal patients between 1992 and 2000 in Kolkata, India}

\author{
Lei Shi, ${ }^{1,7}$ Kazutaka Fujihara, ${ }^{1}$ Toshio Sato, ${ }^{2}$ Hideaki Ito, ${ }^{1,3}$ Pallavi Garg, ${ }^{4}$ \\ Rupa Chakrabarty, ${ }^{4}$ Thandavarayan Ramamurthy, ${ }^{4}$ G. Balakrish Nair, ${ }^{5}$ \\ Yoshifumi Takeda ${ }^{6}$ and Shinji Yamasaki ${ }^{1}$ \\ ${ }^{1}$ Graduate School of Life and Environmental Sciences, Osaka Prefecture University, \\ Gakuen-Cho, Sakai, Osaka 599-8531, Japan \\ ${ }^{2}$ Research Institute, International Medical Center of Japan, Tokyo, Japan \\ ${ }^{3}$ Dainippon Pharmaceutical Co. Ltd., Osaka, Japan \\ ${ }^{4}$ National Institute of Cholera and Enteric Diseases, Calcutta, India \\ ${ }^{5}$ International Center for Diarrhoeal Diseases Research, Dhaka, Bangladesh \\ ${ }^{6}$ Cine-Science Laboratory, Tokyo, Japan \\ ${ }^{7}$ College of Light Industry and Food Technology, South China University and Technology, \\ Guangdong, PR China
}

\begin{abstract}
A total of 133 clinical strains of Vibrio cholerae comprising 44 strains of 01,45 strains of 0139 and 44 strains of non-O1, non-O139 serogroups isolated from hospitalized patients in Kolkata, India, from 1992 to 2000 was examined for the presence of class 1, 2 and 4 integrons. By PCR and DNA sequencing, seven strains of $\mathrm{O} 1$, one strain of $\mathrm{O} 139$ and six strains of non-O1, non-O139 serogroups were found to contain class 1 integron-harbouring genes aadA1, aadA2 (encoding resistance to streptomycin and spectinomycin), blaP1 (resistance to $\beta$-lactams), aar-3 (resistance to rifampicin), aacA4 (resistance to kanamycin and gentamicin), and $d f r A 1$ and $d f A 15$ (resistance to trimethoprim). Most strains produced one or two bands using primers specific for the amplification of the variable region where the antibiotic-resistance genes are located, and their sizes ranged from 700 to $1250 \mathrm{bp}$. However, one strain of $V$. cholerae O1 isolated in 1994 gave a $2483 \mathrm{bp}$ fragment, the largest fragment so far found in a class 1 integron of $V$. cholerae 01 . No strain was positive for the int/2 gene. All $V$. cholerae strains, regardless of serogroup, were positive for the int/4 gene by PCR and using a colony hybridization test. Amplification of the int/4 gene by PCR yielded a 2200 bp fragment (1260 bp larger than the expected size) from three $V$. cholerae $\mathrm{O} 139$ strains isolated in 1999. Sequence analysis of this amplicon revealed an insertion of IS1359 in the middle of the int/4 gene. These data indicate that a class 1 integron is present in some clinical strains of $V$. cholerae isolated in Kolkata, India, and that a class 4 integron is ubiquitously distributed among $V$. cholerae strains regardless of serogroup.
\end{abstract}

\section{INTRODUCTION}

Cholera is a life-threatening illness, particularly among children, in countries with poor sanitation. Before 1992, only the $\mathrm{O} 1$ serogroup of Vibrio cholerae was responsible for causing cholera. However, in 1992, large outbreaks of cholera-like diseases caused by a clonal strain of non-O1 $\mathrm{V}$. cholerae, later designated V. cholerae $\mathrm{O} 139$ synonym Bengal,

Abbreviation: CS, conserved segment.

The GenBank/EMBL/DDBJ accession numbers for the sequences of the genes aacA1c (O1: VC2), aar-3-aacA4-dfrA1-orfc (O1: CO747), dfrA1-orfc (0139: C0406), dfrA1-orfc (non-O1 non-0139: SG6), dfrA15 (non-01 non-O139: C0248), aadA2 (non-01 non-0139: C0248), dfrA1-orfc (non-O1 nonO139: CO775), dfrA1-orfc (non-O1 non-O139: PG92), dfrA15 (non-O1 non-O139: NLC35), blaP1 (non-O1 non-O139: NLC35), aadA2 (non-O1 non-O139: NLC38), blaP1 (non-O1 non-O139: NLC38), int/4-IS1358-int/4 (0139: NLC31), int/4-IS1358-int/4 (0139: NLC40) and int/4-IS1358-int/4 (0139: NLC50) are AB219433, AB219436, AB2 19437, AB2 19453, AB219434, AB2 19435, AB219451, AB2 19452 and AB219454-AB2 19460, respectively. 
emerged from Madras and spread rapidly, not only in India but also to several neighbouring countries (Nair et al., 1996; Ramamurthy et al., 2003). This strain caused an acute secretory disease indistinguishable from that caused by $V$. cholerae $\mathrm{O} 1$, and is now also considered to be a causative agent of classic cholera. It is clearly differentiated from nonO1, non-O139 strains, which are associated with sporadic cases of diarrhoeal diseases. The National Institute of Cholera and Enteric Diseases in Kolkata has conducted identification and molecular characterization of $V$. cholerae from severe diarrhoeal patients admitted to the Infectious Diseases Hospital since the discovery of O139. It was observed that, from time to time, the prevalent serogroup of $V$. cholerae changed from $\mathrm{O} 1$ to $\mathrm{O} 139$ and vice versa (Basu et al., 2000; Mitra et al., 1996; Mukhopadhyay et al., 1995b; Yamasaki et al., 1997). In addition, non-O1, non-O139 strains are sometimes associated with severe diarrhoeal cases indistinguishable from those caused by $V$. cholerae $\mathrm{O} 1$ and O139 serogroups (Mukhopadhyay et al., 1995a; Sharma et al., 1998b).

The use of antibiotics for the treatment of severe cholera is recommended, as it significantly shortens the duration of diarrhoea, reduces the volume of rehydration and maintenance fluids required and decreases the time-length of faecal excretion of $V$. cholerae, which, in turn, reduces the transmission of infection to other contacts (Sack et al., 2004). Antimicrobial agents such as tetracyclines and fluoroquinolones are often used to treat cholera and, in the past, most strains were susceptible to these and other antibiotics used for the treatment of diarrhoeal diseases (O'Grady et al., 1976). However, reports of toxigenic V. cholerae strains resistant to the commonly used antibiotics are appearing with increasing frequency in India, as well as in other countries (Basu et al., 2000; Chakraborty et al., 2001; Dalsgaard et al., 1999a; Garg et al., 2000, 2001; Mitra et al., 1996; Mukhopadhyay et al., 1995b; Ramamurthy et al., 2000; Yamamoto et al., 1995a, b).

Bacteria become resistant to antibiotics by mutation and/or by the acquisition of foreign DNA in the form of plasmids and transposons. In addition, elements known as integrons have been recognized as a mechanism for the acquisition and spread of drug-resistance genes (Hall \& Collis, 1995; Mazel \& Davis, 1999; Ploy et al., 2000; Recchia \& Hall, 1995). An integron consists of three elements, the intI gene encoding an integrase, a recombination site, attI, and a promoter gene. Several classes of integrons have been characterized based on the integrase gene. Classes 1,2 and 3 represent the so-called multi-resistance integrons, and have largely been implicated in the acquisition and dissemination of antibiotic-resistance genes (Ploy et al., 2000). A second type of integron, initially called a class 4 integron, but now termed a super-integron, was identified in a V. cholerae $\mathrm{O} 1$ strain (Mazel et al., 1998), but later was found among other members of the family Vibrionaceae (Rowe-Magnus et al., 2001, 2003). This super-integron contains 179 gene cassettes in a $126 \mathrm{~kb}$ region, which corresponds to $3 \%$ of the total genome, indicating that it may have a role in genome evolution rather than antibiotic resistance (Mazel et al., 1998).

Some information is available about the distribution and importance of class 1 integrons in encoding antibiotic resistance in clinical strains of $V$. cholerae isolated in various geographic areas (Dalsgaard et al., 1999b, 2000a, b, 2001; Ehara et al., 2004; Falbo et al., 1999; Iwanaga et al., 2004; Thungapathra et al., 2002). However, little is known about the distribution and role of integrons in multidrug-resistant $V$. cholerae strains in India (Thungapathra et al., 2002). In this study, we conducted a comprehensive analysis of the distribution of class 1, 2 and 4 integrons, and the relationship to antibiotic resistance in a series of $V$. cholerae strains isolated over a period of time from a single geographical area.

\section{METHODS}

Bacterial strains. A total of 133 clinical strains of $V$. cholerae isolated from acute diarrhoeal patients from 1992 to 2000 in Kolkata, India, was used in this study (Table 1). Three to six strains each of O1, O139 and non-O1, non-O139 serogroups were randomly selected to represent each year from 1992 to 2000. The serogroup of toxigenic $V$. cholerae $\mathrm{O} 1$ or $\mathrm{O} 139$ was reconfirmed by using the multiplex PCR described by Hoshino et al. (1998) using the primer sets described in Table 2. V. cholerae O1 strain SK-10 (for the intI1 gene and 3'-CS) (Dalsgaard et al., 2000a), Escherichia coli carrying the R483:: Tn7 plasmid (intI2) (Falbo et al., 1999) and V. cholerae O1 strain N16961 (intI4) were used for preparation of the DNA probes and as a positive control for each gene. E. coli C600 was used as a negative control in all experiments.

Chemicals, media, enzymes and kits. Chemicals were purchased from Nakalai Tesque, Wako Pure Chemicals or Sigma. Proteinase K was from Nakalai Tesque. Restriction enzymes and Taq DNA polymerase were purchased from Takara Shuzo or New England Biolabs. $\left[\alpha^{-}{ }^{32} \mathrm{P}\right] \mathrm{dCTP}\left(111 \mathrm{TBq} \mathrm{mmol}^{-1}\right)$ was from Perkin Elmer. The Multiprime DNA Labelling System was from Amersham Biosciences and the DNA Labelling and Detection kit was from Roche Diagnostics. The PCR Purification kit was purchased from Qiagen and the Big Dye Terminator Sequencing kit was from Applied Biosystems. NuSieve GTG agarose for the analysis of DNA fragments was from Takara Shuzo. Molecular mass markers for electrophoresis were purchased from Takara Shuzo or Gibco-BRL. Tryptone and yeast extract for L-broth and L-agar were from Difco Laboratories. Thiosulfatecitrate-bile salts-sucrose agar was from Eiken Kagaku.

Antimicrobial susceptibility testing. Antimicrobial susceptibility analysis of $V$. cholerae was performed by a disc diffusion method using commercial discs (Hi Media) with ampicillin $(10 \mu \mathrm{g})$, chloramphenicol $(30 \mu \mathrm{g})$, ciprofloxacin $(5 \mu \mathrm{g})$, co-trimoxazole $(25 \mu \mathrm{g})$, furazolidone $(50 \mu \mathrm{g})$, gentamicin $(10 \mu \mathrm{g})$, nalidixic acid $(30 \mu \mathrm{g})$, neomycin $(30 \mu \mathrm{g})$, norfloxacin $(10 \mu \mathrm{g})$, streptomycin $(10 \mu \mathrm{g})$ and tetracycline $(30 \mu \mathrm{g})$ as described previously (Garg et al., 2000). E. coli ATCC 25922 was used for the quality control of each assay.

PCR amplification. DNA from $V$. cholerae strains used for the PCR template was prepared from overnight L-broth cultures at $37^{\circ} \mathrm{C}$. The culture was diluted tenfold in $10 \mathrm{mM}$ Tris/ $\mathrm{HCl}(\mathrm{pH} 8.0)$ containing $1 \mathrm{mM}$ EDTA and the suspension was boiled for $10 \mathrm{~min}$. After centrifugation at $12000 \mathrm{~g}$ for $3 \mathrm{~min}$, the supernatant was stored at $-20{ }^{\circ} \mathrm{C}$. PCR was carried out in $50 \mu \mathrm{l}$ vols containing $5 \mu \mathrm{l}$ template DNA, $5 \mu \mathrm{l} 10 \times$ concentrated PCR buffer $[100 \mathrm{mM}$ Tris $/ \mathrm{HCl}$ 
Table 1. Distribution of the int $/ 1$, int/2 and int/4 genes in clinical strains of $V$. cholerae isolated from 1992 to 2000 in Kolkata, India

\begin{tabular}{|c|c|c|c|c|c|c|}
\hline \multirow[t]{2}{*}{ Serogroup } & \multirow{2}{*}{$\begin{array}{c}\text { Year of } \\
\text { isolation }\end{array}$} & \multirow{2}{*}{$\begin{array}{l}\text { No. of } \\
\text { strains }\end{array}$} & \multicolumn{4}{|c|}{ No. of strains positive for: } \\
\hline & & & intI1 & intI2 & intI4 & $3^{\prime}-\mathrm{CS}$ \\
\hline \multirow[t]{9}{*}{$\mathrm{O} 1$} & 1992 & 5 & 4 & 0 & 5 & 4 \\
\hline & 1993 & 4 & 2 & 0 & 4 & 2 \\
\hline & 1994 & 5 & 1 & 0 & 5 & 1 \\
\hline & 1995 & 5 & 0 & 0 & 5 & 0 \\
\hline & 1996 & 5 & 0 & 0 & 5 & 0 \\
\hline & 1997 & 5 & 0 & 0 & 5 & 0 \\
\hline & 1998 & 5 & 0 & 0 & 5 & 0 \\
\hline & 1999 & 5 & 0 & 0 & 5 & 0 \\
\hline & 2000 & 5 & 0 & 0 & 5 & 0 \\
\hline Total & & 44 & 7 & 0 & 44 & 7 \\
\hline \multirow[t]{9}{*}{0139} & 1992 & 6 & 1 & 0 & 6 & 1 \\
\hline & 1993 & 5 & 0 & 0 & 5 & 0 \\
\hline & 1994 & 5 & 0 & 0 & 5 & 0 \\
\hline & 1995 & 5 & 0 & 0 & 5 & 0 \\
\hline & 1996 & 4 & 0 & 0 & 4 & 0 \\
\hline & 1997 & 5 & 0 & 0 & 5 & 0 \\
\hline & 1998 & 5 & 0 & 0 & 5 & 0 \\
\hline & 1999 & 5 & 0 & 0 & $5^{*}$ & 0 \\
\hline & 2000 & 5 & 0 & 0 & 5 & 0 \\
\hline Total & & 45 & 1 & 0 & 45 & 1 \\
\hline \multirow[t]{9}{*}{ Non-O1, non-O139 } & 1992 & 6 & 1 & 0 & 6 & 1 \\
\hline & 1993 & 5 & 1 & 0 & 5 & 1 \\
\hline & 1994 & 5 & 1 & 0 & 5 & 1 \\
\hline & 1995 & 5 & 0 & 0 & 5 & 0 \\
\hline & 1996 & 3 & 0 & 0 & 3 & 0 \\
\hline & 1997 & 5 & 0 & 0 & 5 & 0 \\
\hline & 1998 & 5 & 1 & 0 & 5 & 1 \\
\hline & 1999 & 5 & 2 & 0 & 5 & 2 \\
\hline & 2000 & 5 & 0 & 0 & 5 & 0 \\
\hline Total & & 44 & 6 & 0 & 44 & 6 \\
\hline Overall total & & 133 & 14 & 0 & 133 & 14 \\
\hline
\end{tabular}

${ }^{\star}$ Three of the five strains contained IS1359 in the intI4 gene.

(pH 8·3), $500 \mathrm{mM} \mathrm{KCl,} 15 \mathrm{mM} \mathrm{MgCl} 2], 5 \mu \mathrm{l}\left(10 \mathrm{pmol} \mu \mathrm{l}^{-1}\right)$ each of appropriate primers, $4 \mu \mathrm{l}$ dNTP mix $(2 \cdot 5 \mathrm{mM}$ each dNTP), $0 \cdot 25 \mu \mathrm{l}\left(5 \mathrm{U}^{-1}\right)$ Taq DNA polymerase and $25 \cdot 75 \mu \mathrm{l}$ sterilized distilled water. The PCR primers and conditions are given in Table 2. All PCR assays were performed using an automated thermal cycler (GeneAmp PCR System 2400; Applied Biosystems). Primer sets INT-1U/INT-1D, INT-2U/INT-2D and INT-4U/INT-4D were used to detect the conserved regions of the integron-encoded integrase genes intI1, intI2 and intI4, respectively. The primer set qacE $\Delta 1-\mathrm{F}$ and sull-B was used to determine whether the class 1 integron contained the 3'-conserved segment (CS) (Dalsgaard et al., 2000a). Strains yielding PCR products with the primer sets INT-1U/INT-1D and qacE $\Delta 1-\mathrm{F} /$ sull-B were amplified further using the integron primer set in-F/in-B (Dalsgaard et al., 2000a), which amplified the region between the $5^{\prime}$-CS and $3^{\prime}$-CS (Fig. 1). PCR products were analysed by electrophoresis in 1.5 or $3 \%$ agarose gels, stained with ethidium bromide, visualized under UV light and recorded with the aid of a gel documentation system (Bio-Rad).

DNA sequencing and analysis. PCR products were purified using the QIAquick PCR Purification kit (Qiagen) and their nucleotide sequences determined using the BigDye Terminator Cycle Sequencing FS Ready Reaction kit on an ABI PRISM 310 Genetic Analyser (Perkin-Elmer Japan Applied Biosystems). Nucleotide and amino acid sequences were analysed and compared using GenBank and DDBJ sequences and DNASIS software (Hitachi Software Engineering).

Colony hybridization test. A colony hybridization test was carried out as described previously (Mosely et al., 1980) using nitrocellulose membranes (Schleicher \& Schuell) or Hybond-N ${ }^{+}$(Amersham Biosciences) under high-stringency conditions. DNA probes for intIl, intI2, intI4 and $3^{\prime}$-CS were prepared by PCR using the primers described in Table 2, with $V$. cholerae O1 SK-10, E. coli with the R483:: Tn7 plasmid or V. cholerae O1 N16961 as template. PCR products were purified using the QIAquick PCR Purification kit according to the manufacturer's instructions and used as DNA probes. DNA probes were labelled either by random priming using the Multiprime DNA Labelling System and $\left[\alpha_{-}^{32} \mathrm{P}\right] \mathrm{dCTP}$ or with the DNA Labelling and Detection kit.

Preparation of genomic DNA. Genomic DNA from the strains was prepared using the method described by Wilson (1987). 
Table 2. PCR primers used in this study

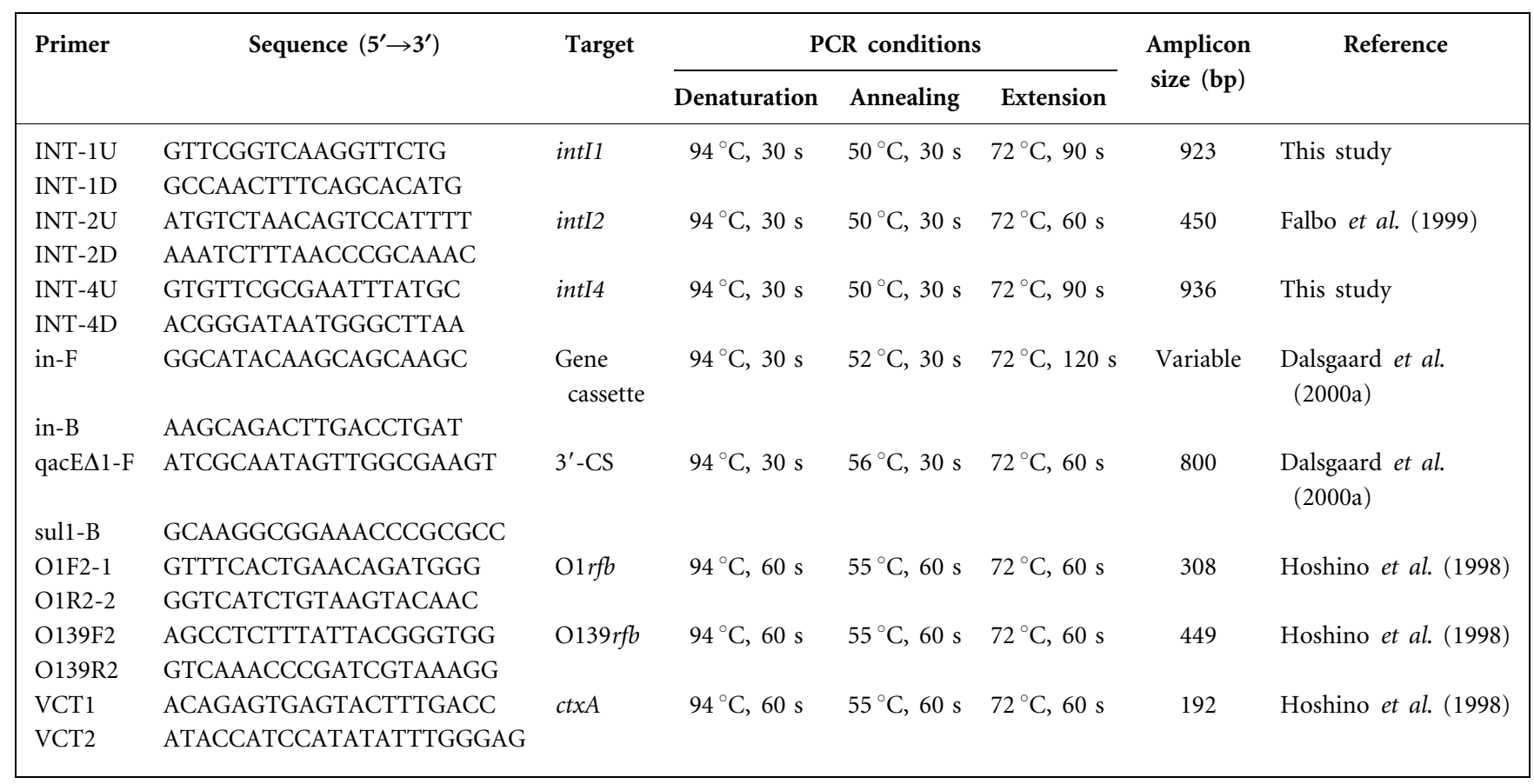

Southern blot hybridization test. Genomic DNA was digested by EcoRI or EcoRV and separated by electrophoresis in a $0.7 \%$ agarose gel. DNA fragments were transferred to a Hybond- $\mathrm{N}^{+}$membrane (Amersham Biosciences) and hybridized under high-stringency conditions with the intI1 gene probe. Radioactivity was analysed using BAS FLA-3000 (Fujifilm).

\section{RESULTS AND DISCUSSION}

The panel of 133 strains of $V$. cholerae $\mathrm{O} 1, \mathrm{O} 139$ and nonO1, non-O139 serogroups was analysed for the distribution of class 1, 2 and 4 integrons (Table 1) and for resistance to antimicrobial agents (data not shown). Most of the strains were multidrug resistant (three or more drugs) with several combinations of resistance. In $V$. cholerae $\mathrm{O} 1$, the rate of multidrug resistance increased year by year: the six strains isolated before 1993 were resistant to only one or two antimicrobial agents tested, whilst the 38 strains isolated after 1993 were multidrug resistant. However, antimicrobial profiles of $V$. cholerae $\mathrm{O} 139$ and non-O1, non-O139 serogroups varied irrespective of the year of isolation. Nineteen and 28 strains of $\mathrm{O} 139$ and non-O1, non-O139, respectively, were resistant to one or two antimicrobial agents tested, whilst 26 and 16 were resistant to three to five drugs, respectively.

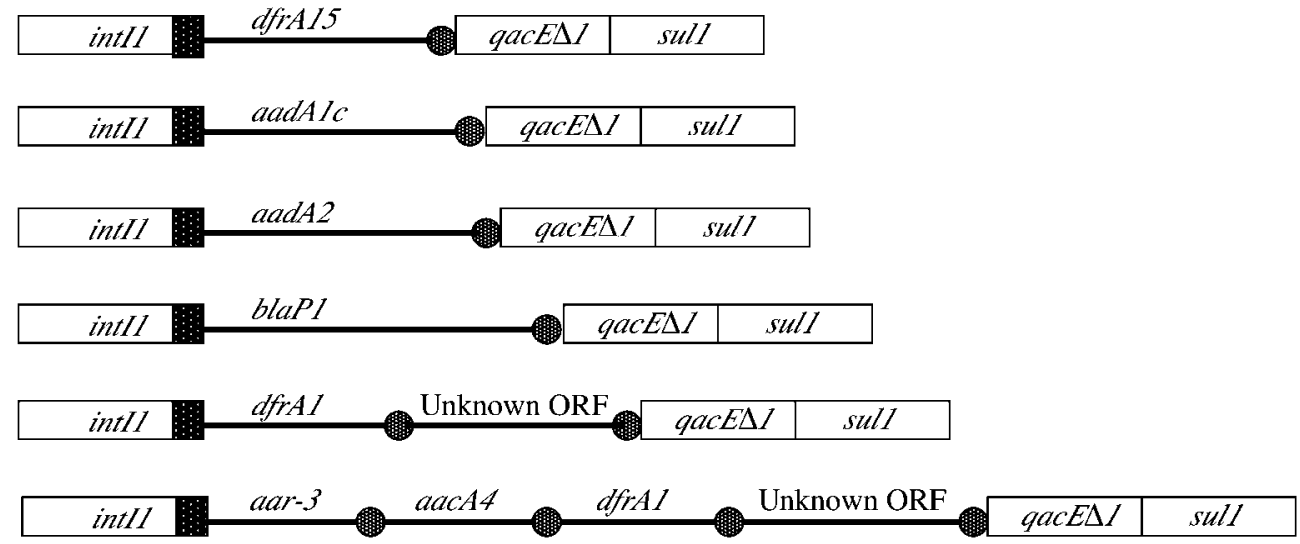

Fig. 1. Class 1 integron structure and resistance gene cassettes found in $V$. cholerae $\mathrm{O} 1, \mathrm{O} 139$ and non-O1, non-O139 strains. The $5^{\prime}$-CS (containing the int/1 gene) and the $3^{\prime}$-CS (containing the qacE $\Delta 1$ and sul1 genes) are shown by open boxes. Att1 sites are indicated by a filled bar at the end of the integrase 1 (int/1) gene. The individual gene cassettes are shown together with their recombination sites, a 59 bp element indicated by a circle. 
A correlation between antimicrobial resistance and the presence of integrons was explored by PCR and/or colony hybridization tests for the intI1 and intI2 genes. Although none of the strains produced an amplicon of the intI2 gene, a fragment of $\sim 900 \mathrm{bp}$ corresponding to the intI1 gene was amplified from 14 strains using the INT-IU and INT-ID primers (data not shown). Table 1 shows that, among 44 strains of the O1 serogroup, four strains isolated in 1992, two strains isolated in 1993 and one strain from 1994 were positive for the intI1 gene. Although O139 strains have not been reported in the literature to be positive for class 1 integrons (Dalsgaard et al., 2000a), one of the 45 O139 strains tested in this series, which was isolated in 1992, tested positive for the presence of the intII gene. This is the first report, to our knowledge, of this class of integron in this serogroup. Six out of 44 non-O1, non-O139 strains harboured the intI1 gene (Table 1). The $900 \mathrm{bp}$ fragment of the intI1 gene obtained from the 14 strains was sequenced and confirmed to be identical to the sequence of the intI1 gene reported previously (data not shown). To confirm whether a complete class 1 integron exists in intI1-positive $V$. cholerae strains, 3 '-CS, which contains the qacE 1 and sull genes, was also amplified using the primer set indicated in Table 2. Each of the 14 strains positive for the intI1 gene gave a fragment of $\sim 800 \mathrm{bp}$, which corresponds to the expected size of $3^{\prime}$-CS (data not shown). A colony hybridization test with intI1 and $3^{\prime}$-CS gene probes also confirmed the presence of the integron in these strains. Although a class 1 integron may not always contain the entire 3'-CS segment, these $14 \mathrm{~V}$. cholerae strains isolated in India possessed a complete class 1 integron.

The presence of a class 1 integron varied among serogroups. For example, seven of the $V$. cholerae $\mathrm{O} 1$ strains isolated between 1992 and 1994 were positive for class 1 integron, corresponding to $50 \%$ of the isolates recovered in this period. Our findings are in agreement with Amita et al. (2003), who reported that the class 1 integron was widely distributed among $\mathrm{O} 1$ strains isolated in India before the initial O139 outbreak in 1992, but was less frequent in O1 strains isolated after that year. Similar observations have also been reported from other Asian countries for isolates from 1992 to 1996, including Laos (1993-1996) (Iwanaga et al., 2004), Albania and Italy (1994) (Falbo et al., 1999), Vietnam (1994-1996) (Dalsgaard et al., 1999b; Ehara et al., 2004) and Thailand (1992-1996) (Dalsgaard et al., 2000a). None of the $V$. cholerae O1 strains isolated after 1998 in Vietnam and Laos was positive for the class 1 integron (Ehara et al., 2004; Iwanaga et al., 2004). However, V. cholerae O1 strains isolated in Guinea-Bissau (1996-1997) (Dalsgaard et al., 2000b) and in 1998 in Mozambique and South Africa (Sharma et al., 1998a) contained a class 1 integron. These data indicate that $V$. cholerae $\mathrm{O} 1$ strains carrying this integron in Asian countries before 1996 may have spread to Africa, as has been suggested by others (Dalsgaard et al., 2001; Sharma et al., 1998b).

A class 1 integron was also detected in $14 \%$ of $V$. cholerae non-O1, non-O139 strains in this study. Thungapathra et al.
(2002) reported that $23 \%(22 / 94)$ of non-O1, non-O139 strains isolated in India between 1997 and 1998 contained a class 1 integron. In Thailand, $30 \%$ of isolates of these serogroups isolated from children between 1993 and 1995 were positive compared with $58 \%$ of the strains from adult patients in 1990 (Dalsgaard et al., 2000a). However, in the last study, 45 environmental strains from water, sediment and seafood samples did not contain a class 1 integron, and only one strain isolated from a seafood sample was positive for the element (Dalsgaard et al., 2000a). No environmental strains isolated in India were examined for a class 1 integron in this study.

Since all of the 14 strains carried a complete class 1 integron, we attempted to amplify the variable region to examine the nature of antimicrobial-resistance genes located in the region by using the in-F/in-B primer set shown in Table 2 . Amplification of the integron gene cassette of seven intI1positive $\mathrm{O} 1$ strains yielded a fragment of approximately $1.0 \mathrm{~kb}(\mathrm{VC} 2, \mathrm{VC} 12, \mathrm{VC} 18, \mathrm{VC} 19, \mathrm{CO} 361$ and $\mathrm{CO} 371)$ or $2.5 \mathrm{~kb}$ (CO747), the largest amplicon so far reported in $V$. cholerae (Fig. 2a). Nucleotide sequence analysis revealed that the $1.0 \mathrm{~kb}$ fragment contained $1009 \mathrm{bp}$ harbouring the aadA1 gene homologue, which is responsible for streptomycin and spectinomycin resistance, and that the $2.5 \mathrm{~kb}$ fragment contained $2483 \mathrm{bp}$ comprising the aar-3, aacA4, $d f r A 1$ and $o r f c$ genes responsible, respectively, for rifampicin, kanamycin and gentamicin, and trimethoprim resistance, and an unknown ORF (Table 3, Fig. 1). Since the aadA1 gene homologue differed by 6 and $10 \mathrm{nt}$ from aadA1a (GenBank accession no. X12870) and aadAlb (GenBank accession no. M95287), respectively, the aadA1 gene homologue from this study was designated aadA1c. Similar amplification of the gene cassette of the intI1-positive strain of $V$. cholerae $\mathrm{O} 139$ gave a fragment of $\sim 1 \cdot 2 \mathrm{~kb}$ (Fig. 2a), which on sequence analysis was revealed to be $1242 \mathrm{bp}$ and harboured the $d f r A 1$ and orfc genes responsible for trimethoprim resistance and an unknown ORF, respectively (Table 3). Three of the six strains of non-O1, non-O139 serogroup also gave an amplicon of approximately $1 \cdot 2 \mathrm{~kb}$, and the remainder were characterized by two amplicons in different combinations and of different sizes of approximately $0 \cdot 7,1 \cdot 0$ and $1.2 \mathrm{~kb}$ (Fig. $2 \mathrm{~b}$ ). The nucleotide sequence of the $1.2 \mathrm{~kb}$ fragment confirmed that three strains (SG6, CO775 and PG92) harboured the $d f r A 1$ and orfc genes identical to those of the O139 strain (Table 3, Fig. 2b). Sequence analysis of the other three strains showed that the $0.7 \mathrm{~kb}$ fragment (739 bp) contained the $d f r A 15$ gene (trimethoprim resistance), the $1.0 \mathrm{~kb}$ fragment (1009 bp) equated to the aadA2 gene (streptomycin and spectinomycin resistance) and the $1.2 \mathrm{~kb}$ fragment (1197 bp) equated to the blaP1 gene, which encodes $\beta$-lactam resistance. In general, there was good correlation between the antibiotic-resistant phenotype and the presence of drug-resistance genes in the class 1 integron. However, the aacA4 gene, which encodes kanamycin and gentamicin resistance and was present in the integron of $\mathrm{O} 1$ strain $\mathrm{CO} 747$, did not show phenotypic resistance to these antibiotics. The detailed arrangement of 
(a)

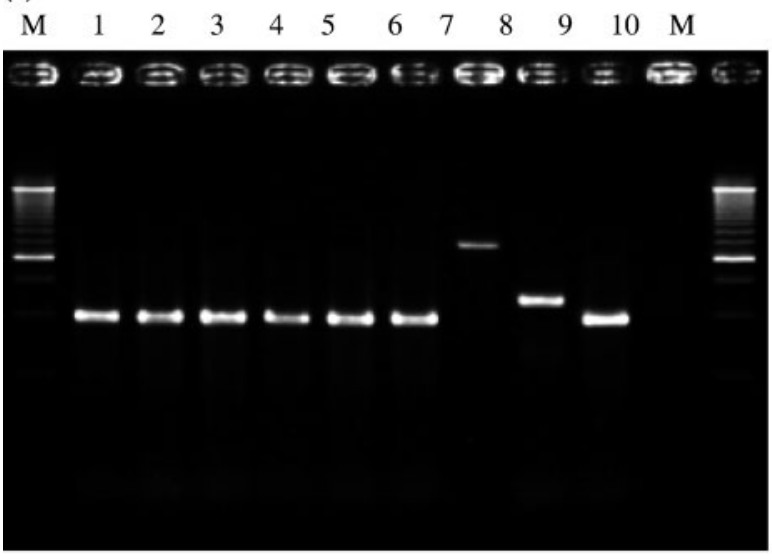

(b)

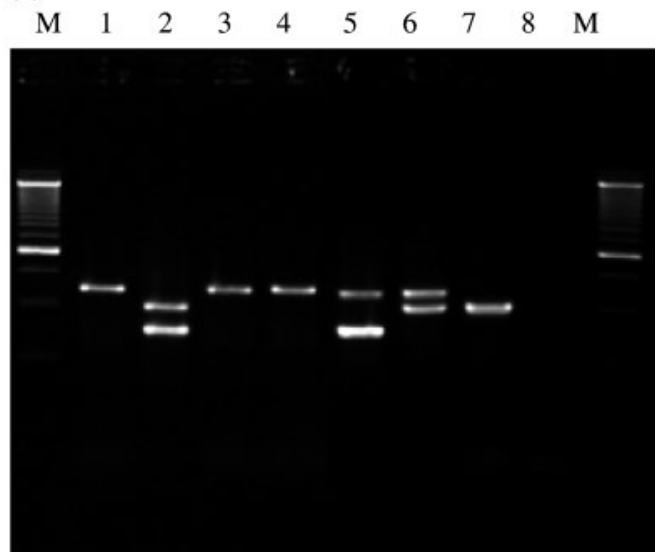

Fig. 2. $P C R$ amplification using the in $-F$ and in-B primers specific for the variable region in the class 1 integron in $V$. cholerae O1 and O139 (a), and non-O1, non-O139 serogroups (b). (a) Lanes: M, 500 bp ladder; 1, O1 VC2 (1992); 2,01 VC12 (1992); 3, O1 VC18 (1992); 4, O1 VC19 (1992); 5, O1 CO361 (1993); 6, O1 CO371 (1993); 7, O1 CO747 (1994); 8, O139 CO406 (1992); 9, O1 SK-10; 10, E. coli C600. (b) Lanes: M, 500 bp ladder; 1, SG6 (1992); 2, CO248 (1993); 3, CO775 (1994); 4, PG92 (1998); 5, NLC35 (1999); 6, NLC38 (1999); 7, O1 SK-10; 8, E. coli C600.

the class I integrons revealed by this study is shown in Fig. 1 and Table 3.

The aadA1c gene, which confers resistance to streptomycin and spectinomycin, was predominant in $V$. cholerae $\mathrm{O} 1$ strains isolated in India. This gene, together with aadA2, has also been reported in a class 1 integron found in $\mathrm{O} 1$ strains in Laos (Iwanaga et al., 2004), Vietnam (Dalsgaard et al., 1999b; Ehara et al., 2004) and Thailand (Dalsgaard et al., 2000a). However, the class 1 integron found in O1 strains from Guinea-Bissau contained $d f r A 1$ and orfc genes (Dalsgaard et al., 2000b), which were more frequent in non-O1 strains in India. Although all $44 \mathrm{O} 1$ strains investigated were resistant to streptomycin, 37 did not contain a class 1 integron, indicating that other mechanisms also contribute to this resistance. Since all of the O1 strains isolated after 1993 were resistant to trimethoprim, a possible explanation is that an SXT constin, a conjugative,

Table 3. Resistance gene cassettes found in $V$. cholerae strains containing class 1 integron

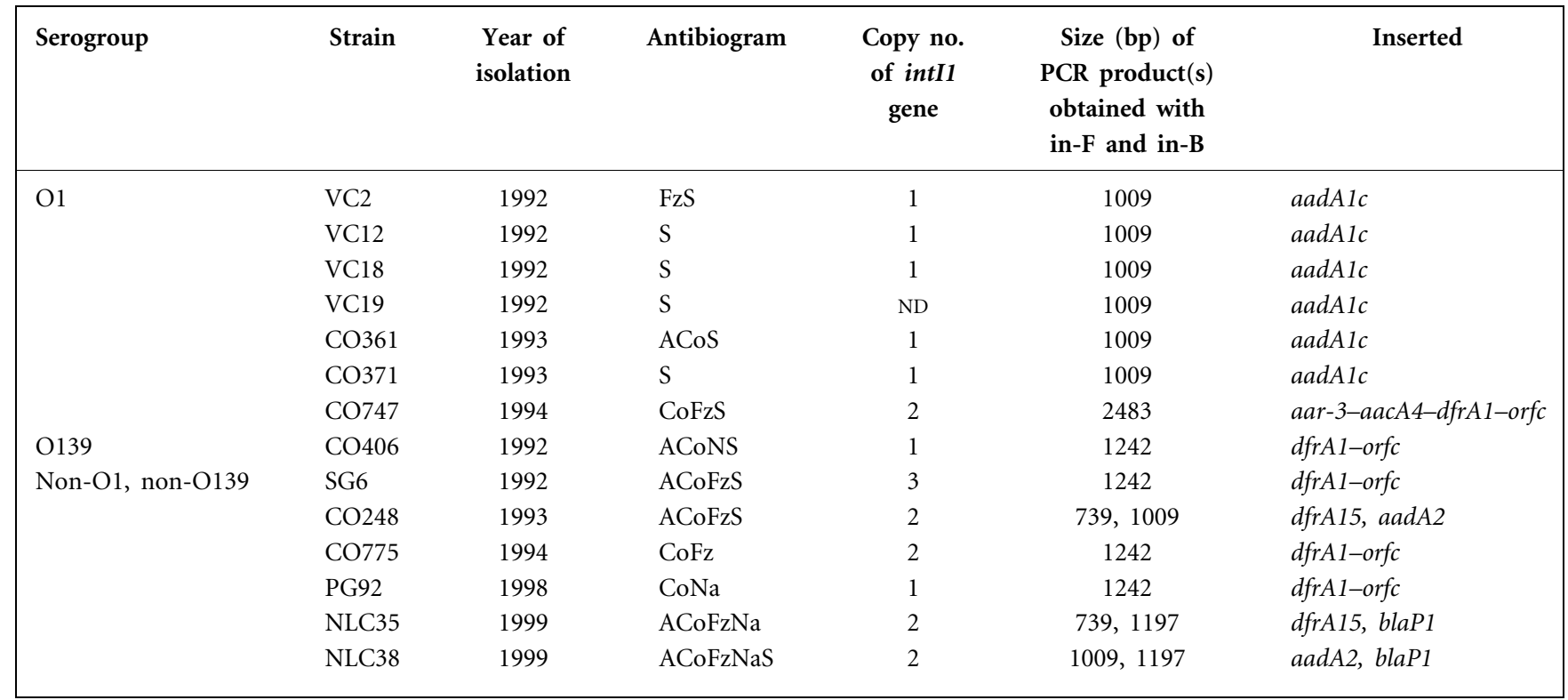

A, Ampicillin; C, chloramphenicol; Cf, ciprofloxacin; Co, co-trimoxazole; Fz, furazolidone; G, gentamicin; Na, nalidixic acid; N, neomycin; Nx, norfloxacin; S, streptomycin; T, tetracycline; ND, not determined. 
self-transmissible, integrating element harbouring resistance determinants to trimethoprim, streptomycin, sulfamethoxazole and chloramphenicol (Hochhut et al., 2001; Waldor et al., 1996), may have contributed to streptomycin and trimethoprim resistance in strains lacking the integron. These SXT elements have been reported to be frequent in $\mathrm{O} 1$ strains isolated after the initial O139 epidemic (Amita et al., 2003).

Two amplicons were obtained with the in-F/in-B primer set for three non-O1, non-O139 strains. Since two copies of the intI1 gene have been found in Thai non-O1, non-O139 strains (Dalsgaard et al., 2000a), hybridization with the intI1 gene probe was performed with 14 intI1-positive $V$. cholerae strains. As no EcoRI and EcoRV sites are present in the sequence of the intI1 gene, the number of reactive bands obtained by EcoRI or EcoRV digestion is a good indicator of the copy number of this gene. Two intIl genes were detected in a single O1 strain (CO747; Table 3, Fig. 3) and in four out of five non-O1, non-O139 strains, and one strain of the latter serogroup carried three copies (Table 3). These data indicated that two amplicons obtained by the in-F/in-B primer set were derived from a class 1 integron and that two or more copies of the integron are present in some $V$. cholerae strains. However, these results may indicate that the same resistance gene or no gene cassette was present in some class 1 integrons. The $d f r A 15$, aadA2 and blaP1 genes found in Indian strains have also been reported in Thai non-O1, non-O139 strains (Dalsgaard et al., 2000a), which is supportive of a similar strain in these countries. Thungapathra et al. (2002) reported that additional

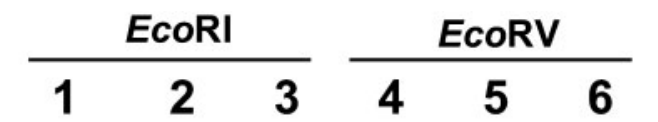

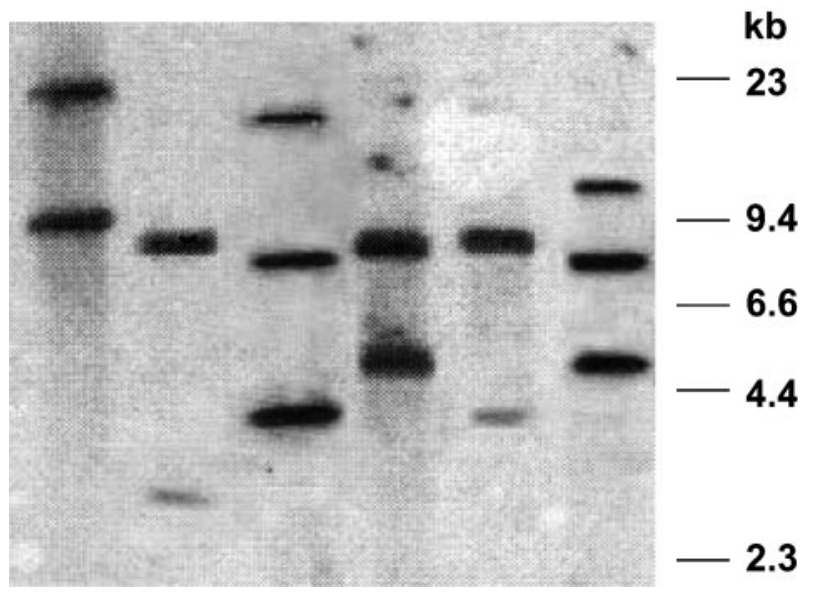

Fig. 3. Southern blot hybridization test for the detection of the int/1 gene after restriction digestion of genomic DNA of $V$. cholerae strains. Lanes: 1-3, EcoRI digest of CO747, CO775 and SG6, respectively; 4-6, EcoRV digest of CO747, CO775 and SG6, respectively. resistance gene cassettes, such as aadA1, aac (6 $\left.6^{\prime}\right)-I b, d f r A 5$ and $\operatorname{ere} A 2$, and $d f r A 12$, orfc and $\operatorname{aad} A 2$ genes were present among $V$. cholerae non-O1, non-O139 strains isolated in India between 1997 and 1998.

Analysis of the V. cholerae O1 El Tor strain N16961 genome sequence showed that a super-integron structure with 179 gene cassettes upstream of an integrase gene and of $\sim 130 \mathrm{~kb}$ corresponds to about $3 \%$ of the genome. Mazel et al. (1998) speculated that this super-intregron might be responsible for genome evolution rather than the capture of antibioticresistance genes. The presence of the intI4 gene, which is associated with the super-integron, was examined by PCR to establish its frequency in different $V$. cholerae serogroups. Most of the strains gave a fragment of $\sim 900 \mathrm{bp}$, which is the expected size of intI4 (Table 2). However, three O139 strains isolated in 1999 produced a fragment of $\sim 2200$ bp (Fig. 4), which is $1.3 \mathrm{~kb}$ larger than the expected size. These results were confirmed by colony hybridization, which showed that all strains were positive for the gene, regardless of serogroup, suggesting that the intI4 gene is ubiquitous in the species. Nucleotide sequence analysis of both fragments revealed that the $936 \mathrm{bp}$ fragment was identical to the intI4 gene. The large fragment contained $2196 \mathrm{nt}$ with an insertion of IS 1359 in the intI4 gene, as shown in Fig. 5, indicating that the active form of integrase 4 cannot be translated. However, the exact function of the super-integron is not yet known and these strains may prove useful for further structure and function studies.

In conclusion, we have demonstrated that class 1 integrons containing different antibiotic-resistance gene cassettes are distributed among clinical strains of $V$. cholerae $\mathrm{O} 1, \mathrm{O} 139$ and non-O1, non-O139 isolated in India. The role of these

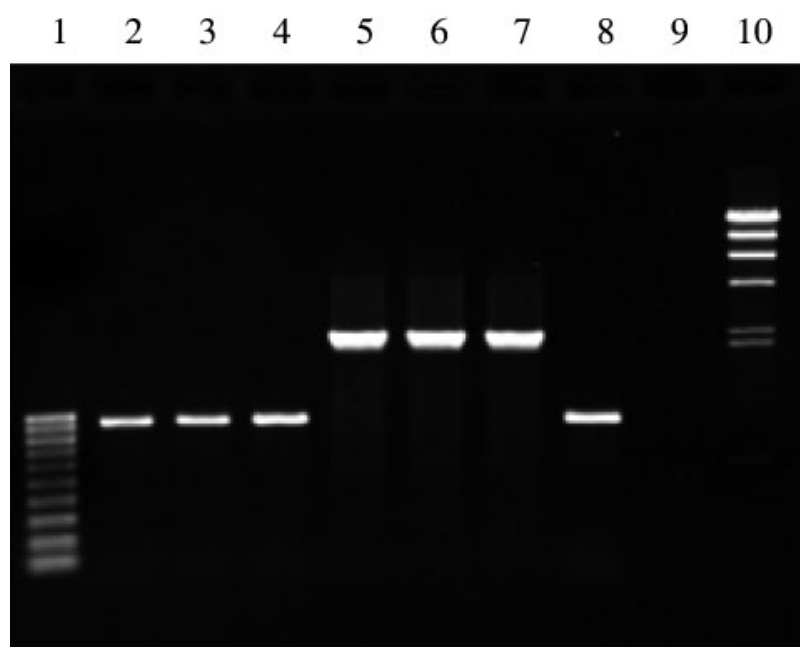

Fig. 4. Detection of int/4 genes among $V$. cholerae strains by PCR. Lanes: 1, 100 bp ladder; 2, O1 VC2 (1992); 3, O139 CO406 (1992); 4, non-O1, non-O139 CO248 (1993); 5, O139 NLC50 (1999); 6, O139 NLC31 (1999); 7, O139 NLC40 (1999); 8, O1 N16961; 9, E. coli C600; 10, $\lambda$ Hindlll digest. 


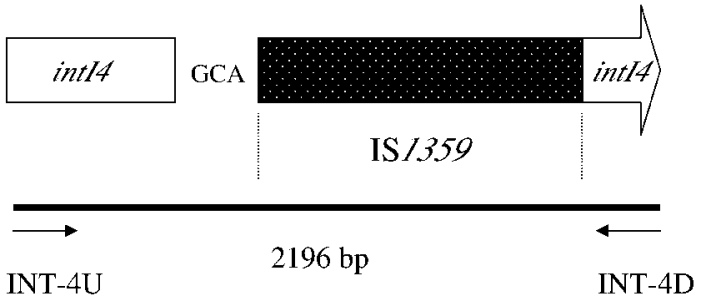

Fig. 5. Schematic representation of IS1359 inserted in the middle of the integrase 4 (int/4) gene of $V$. cholerae 0139.

integrons in the dissemination of antibiotic-resistance genes appears to be less significant for $\mathrm{O} 1$ and $\mathrm{O} 139$ serogroups and their presence accounted for resistance to relatively few drugs. This suggests that other determinants of antibiotic resistance are functional in these strains. PCR mapping of integrons and DNA sequencing of their genetic content may be a useful epidemiological tool to study the dissemination of antibiotic-resistance genes within $V$. cholerae.

\section{ACKNOWLEDGEMENTS}

We thank Drs A. Forslund and V. Falbo for providing strains of $V$. cholerae SK-10 and E. coli containing intI1 and intI2 genes, respectively. L.S. was a post-doctoral research fellow supported by the Health Science Foundation, Japan. This work was supported by a Health Sciences Research Grant on Emerging and Re-emerging Infectious Diseases, a grant-in-aid for Scientific Research from the Ministry of Education, Science, Sports and Culture of Japan, and Japan International Co-operation Agency (JICA/NICED project 054-1061-E-0).

\section{REFERENCES}

Amita, Chowdhury, S. R., Thungapathra, M., Ramamurthy, T., Nair, G. B. \& Ghosh, A. (2003). Class 1 integrons and SXT elements in El Tor strains isolated before and after 1992 Vibrio cholerae O139 outbreak, Calcutta, India. Emerg Infect Dis 9, 500-502.

Basu, A., Garg, P., Datta, S. \& 8 other authors (2000). Vibrio cholerae O139 in Calcutta, 1992-1998: incidence, antibiograms, and genotypes. Emerg Infect Dis 6, 139-147.

Chakraborty, S., Garg, P., Ramamurthy, T. \& 9 other authors (2001). Comparison of antibiogram, virulence genes, ribotypes and DNA fingerprints of Vibrio cholerae of matching serogroups isolated from hospitalised diarrhoea cases and from the environment during 1997-1998 in Calcutta, India. J Med Microbiol 50, 879-888.

Dalsgaard, A., Forslund, A., Bodhidatta, L., Serichantalergs, O., Pitarangsi, C., Pang, L., Shimada, T. \& Echeverria, P. (1999a). A high proportion of Vibrio cholerae strains isolated from children with diarrhoea in Bangkok, Thailand are multiple antibiotic resistant and belong to heterogenous non-O1, non-O139 O-serotypes. Epidemiol Infect 122, 217-226.

Dalsgaard, A., Forslund, A., Tam, N. V., Vinh, D. X. \& Cam, P. D. (1999b). Cholera in Vietnam: changes in genotypes and emergence of class I integrons containing aminoglycoside resistance gene cassettes in Vibrio cholerae O1 strains isolated from 1979 to 1996. J Clin Microbiol 37, 734-741.

Dalsgaard, A., Forslund, A., Serichantalergs, O. \& Sandvang, D. (2000a). Distribution and content of class 1 integrons in different
Vibrio cholerae O-serotype strains isolated in Thailand. Antimicrob Agents Chemother 44, 1315-1321.

Dalsgaard, A., Forslund, A., Petersen, A. \& 7 other authors (2000b). Class 1 integron-borne, multiple-antibiotic resistance encoded by a 150-kilobase conjugative plasmid in epidemic Vibrio cholerae O1 strains isolated in Guinea-Bissau. J Clin Microbiol 38, 3774-3779.

Dalsgaard, A., Forslund, A., Sandvang, D., Arntzen, L. \& Keddy, K. (2001). Vibrio cholerae O1 outbreak isolates in Mozambique and South Africa in 1998 are multiple-drug resistant, contain the SXT element and the aadA2 gene located on class 1 integrons. J Antimicrob Chemother 48, 827-838.

Ehara, M., Nguyen, B. M., Nguyen, D. T., Toma, C., Higa, N. \& Iwanaga, M. (2004). Drug susceptibility and its genetic basis in epidemic Vibrio cholerae $\mathrm{O} 1$ in Vietnam. Epidemiol Infect 132, 595-600.

Falbo, V., Carattoli, A., Tosini, F., Pezzella, C., Dionisi, A. M. \& Luzzi, I. (1999). Antibiotic resistance conferred by a conjugative plasmid and a class I integron in Vibrio cholerae O1 El Tor strains isolated in Albania and Italy. Antimicrob Agents Chemother 43, 693-696.

Garg, P., Chakraborty, S., Basu, I. \& 8 other authors (2000). Expanding multiple antibiotic resistance among clinical strains of Vibrio cholerae isolated from 1992-7 in Calcutta, India. Epidemiol Infect 124, 393-399.

Garg, P., Sinha, S., Chakraborty, R., Bhattacharya, S. K., Nair, G. B., Ramamurthy, T. \& Takeda, Y. (2001). Emergence of fluoroquinolone-resistant strains of Vibrio cholerae O1 biotype El Tor among hospitalized patients with cholera in Calcutta, India. Antimicrob Agents Chemother 45, 1605-1606.

Hall, R. M. \& Collis, C. M. (1995). Mobile gene cassettes and integrons: capture and spread of genes by site-specific recombination. Mol Microbiol 15, 593-600.

Hochhut, B., Lotfi, Y., Mazel, D., Faruque, S. M., Woodgate, R. \& Waldor, M. K. (2001). Molecular analysis of antibiotic resistance gene clusters in Vibrio cholerae O139 and O1 SXT constins. Antimicrob Agents Chemother 45, 2991-3000.

Hoshino, K., Yamasaki, S., Mukhopadhyay, A. K., Chakraborty, S., Basu, A., Bhattacharya, S. K., Nair, G. B., Shimada, T. \& Takeda, Y. (1998). Development and evaluation of a multiplex PCR assay for rapid detection of toxigenic Vibrio cholerae O1 and O139. FEMS Immunol Med Microbiol 20, 201-207.

Iwanaga, M., Toma, C., Miyazato, T., Insisiengmay, S., Nakasone, N. \& Ehara, M. (2004). Antibiotic resistance conferred by a class 1 integron and SXT constin in Vibrio cholerae O1 strains isolated in Laos. Antimicrob Agents Chemother 48, 2364-2369.

Mazel, D. \& Davis, J. (1999). Antibiotic resistance in microbes. Cell Mol Life Sci 56, 742-754.

Mazel, D., Dychinco, B., Webb, V. A. \& Davis, J. (1998). A distinctive class of integron in the Vibrio cholerae genome. Science 280, 605-608.

Mitra, R., Basu, A., Dutta, D., Nair, G. B. \& Takeda, Y. (1996). Resurgence of Vibrio cholerae O139 Bengal with altered antibiogram in Calcutta, India. Lancet 348, 1181.

Mosely, S. L., Huq, I., Alim, A. R. M. A., So, M., Samadpour-Motalebi, M. \& Falkow, S. (1980). Detection of enterotoxigenic Escherichia coli by DNA colony hybridization. J Infect Dis 142, 892-898.

Mukhopadhyay, A. K., Saha, P. K., Garg, S., Bhattacharya, S. K., Shimada, T., Takeda, T., Takeda, Y. \& Nair, G. B. (1995a). Distribution and virulence of Vibrio cholerae belonging to serogroups other than O1 and O139: a nationwide survey. Epidemiol Infect 114, 65-70. Mukhopadhyay, A. K., Garg, S., Nair, G. B. \& 7 other authors (1995b). Biotype traits and antibiotic susceptibility of Vibrio cholerae serogroup O1 before, during and after the emergence of the O139 serogroup. Epidemiol Infect 115, 427-434. 
Nair, G. B., Albert, M. J., Shimada, T. \& Takeda, Y. (1996). Vibrio cholerae O139 Bengal: the new serogroup causing cholera. Rev Med Microbiol 7, 43-51.

O’Grady, F., Lewis, M. J. \& Perarson, N. J. (1976). Global surveillance of antibiotic sensitivity of Vibrio cholerae. Bull W H O 54, 181-185.

Ploy, M.-C., Lambert, T., Couty, J.-P. \& Denis, F. (2000). Integrons: an antibiotic resistance gene capture and expression. Clin Chem Lab Med 38, 483-487.

Ramamurthy, T., Rajendran, K., Garg, P. \& 8 other authors (2000). Cluster-analysis and patterns of dissemination of multidrug resistance among clinical strains of Vibrio cholerae in Calcutta, India. Indian J Med Res 112, 78-85.

Ramamurthy, T., Yamasaki, S., Takeda, Y. \& Nair, G. B. (2003). Vibrio cholerae O139 Bengal: odyssey of a fortuitous variant. Microbes Infect 5, 329-344.

Recchia, G. D. \& Hall, R. M. (1995). Gene cassettes: a new class of mobile element. Microbiology 141, 3015-3027.

Rowe-Magnus, D. A., Guerout, A.-M., Ploncard, P., Dychinco, B., Davies, J. \& Mazel, D. (2001). The evolutionary history of chromosomal super-integrons provides an ancestry for multiresistant integrons. Proc Natl Acad Sci U S A 98, 652-657.

Rowe-Magnus, D. A., Guerout, A.-M., Biskri, L., Bouige, P. \& Mazel, D. (2003). Comparative analysis of superintegrons: engineering extensive genetic diversity in the Vibrionaceae. Genome Res 13, 428-442.

Sack, D. A., Sack, R. B., Nair, G. B. \& Siddique, A. K. (2004). Cholera. Lancet 363, 223-233.

Sharma, C., Thungapathra, M., Ghosh, A. \& 11 other authors (1998a). Molecular analysis of non-O1, non-O139 Vibrio cholerae associated with an unusual upsurge in the incidence of cholera-like disease in Calcutta, India. J Clin Microbiol 36, 756-763.

Sharma, C., Ghosh, A., Dalsgaard, A., Forslund, A., Ghosh, R. K., Bhattacharya, S. K. \& Nair, G. B. (1998b). Molecular evidence that a distinct Vibrio cholerae O1 biotype El Tor strain in Calcutta may have spread to the African continent. J Clin Microbiol 36, 843-844.

Thungapathra, M., Amita, Sinha, K. K., Chaudhuri, S. R., Garg, P., Ramamurthy, T., Nair, G. B. \& Ghosh, A. (2002). Occurrence of antibiotic resistance gene cassettes aac $\left(6^{\prime}\right)-I b, d f r A 5, d f r A 12$, and ereA2 in class I integrons in non-O1, non-O139 Vibrio cholerae strains in India. Antimicrob Agents Chemother 46, 2948-2955.

Waldor, M. K., Tschaepe, H. \& Mekalanos, J. J. (1996). A new type of conjugative transposon encodes resistance to sulfamethoxazole, trimethoprim, and streptomycin in Vibrio cholerae O139. J Bacteriol 178, 4157-4165.

Wilson, K. (1987). Preparation of genomic DNA from bacteria. In Current Protocols in Molecular Biology, pp. 2.4.1.-2.4.5. Edited by F. M. Ausubel, R. Brent, R. E. Kingston, D. D. Moore, J. G. Seidman, J. A. Smith \& K. Struhl. New York: Wiley Interscience.

Yamamoto, T., Nair, G. B. \& Takeda, Y. (1995a). Emergence of tetracycline resistance due to a multiple drug resistance plasmid in Vibrio cholerae O139. FEMS Immunol Med Microbiol 11, 131-136.

Yamamoto, T., Nair, G. B., Albert, M. J., Parodi, C. C. \& Takeda, Y. (1995b). Survey of in vitro susceptibilities of Vibrio cholerae O1 and O139 to antimicrobial agents. Antimicrob Agents Chemother 39, 241-244.

Yamasaki, S., Nair, G. B., Bhattacharya, S. K., Yamamoto, S., Kurazono, H. \& Takeda, Y. (1997). Cryptic appearance of a new clone of Vibrio cholerae serogroup O1 biotype El Tor in Calcutta, India. Microbiol Immunol 41, 1-6. 